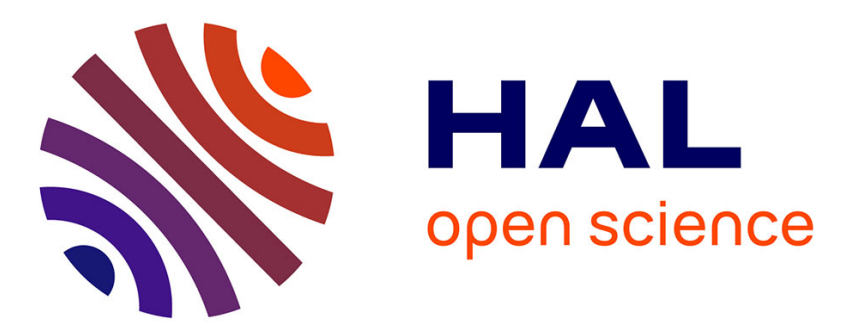

\title{
Acrylamide content of selected Spanish foods: A survey of biscuits and bread derivatives
}

Jose A. Rufian-Henares, Gema Arribas-Lorenzo, Francisco J. Morales

\section{To cite this version:}

Jose A. Rufian-Henares, Gema Arribas-Lorenzo, Francisco J. Morales. Acrylamide content of selected Spanish foods: A survey of biscuits and bread derivatives. Food Additives and Contaminants, 2007, 24 (04), pp.343-350. 10.1080/02652030601101169 . hal-00577306

\section{HAL Id: hal-00577306 https://hal.science/hal-00577306}

Submitted on 17 Mar 2011

HAL is a multi-disciplinary open access archive for the deposit and dissemination of scientific research documents, whether they are published or not. The documents may come from teaching and research institutions in France or abroad, or from public or private research centers.
L'archive ouverte pluridisciplinaire HAL, est destinée au dépôt et à la diffusion de documents scientifiques de niveau recherche, publiés ou non, émanant des établissements d'enseignement et de recherche français ou étrangers, des laboratoires publics ou privés. 


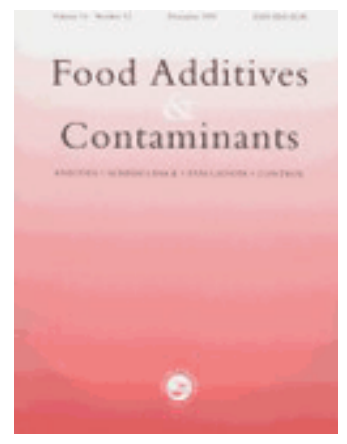

\section{Acrylamide content of selected Spanish foods: A survey of biscuits and bread derivatives}

\begin{tabular}{|r|l|}
\hline Journal: & Food Additives and Contaminants \\
\hline Manuscript ID: & TFAC-2006-252.R1 \\
\hline Manuscript Type: & Original Research Paper \\
\hline Author: & 24-Oct-2006 \\
\hline Complete List of Authors: & $\begin{array}{l}\text { Rufian-Henares, Jose A.; Consejo Superior de Investigaciones } \\
\text { Cientificas, Instituto del Frio } \\
\text { Arribas-Lorenzo, Gema; Consejo Superior de Investigaciones } \\
\text { Cientificas, Instituto del Frio } \\
\text { Morales, Francisco J.; Consejo Superior de Investigaciones } \\
\text { Cientificas, Instituto del Frio }\end{array}$ \\
\hline Mdditives/Contaminants: & Acrylamide \\
\hline Food Types: & Biscuits, Bread, Cereals \\
\hline Fodsochniques: & \\
\hline
\end{tabular}

\section{SCHOLARONE Manuscripts}




\section{Acrylamide content of selected Spanish foods: A survey of biscuits and 2 bread derivatives}

3

4 Francisco J Morales, Jose A Rufian-Henares and Gema Arribas-Lorenzo 5

6 Consejo Superior de Investigaciones Cientificas - Instituto del Frio 7 Jose Antonio Novais 10 Madrid 28040, Spain

\section{Abstract}

11 An overview of the acrylamide content in commercial biscuits and bread derivatives

12 (bread sticks, bread crust, crackers) marketed in Spain is presented. Acrylamide was 13 determined by stable isotope dilution LC-MS with an LOQ of $30 \mu \mathrm{g} \mathrm{kg}^{-1}$. Acrylamide 14 content ranged from $<$ LOQ $-2085 \mu \mathrm{g} \mathrm{kg}^{-1}$, <LOQ $-151 \mu \mathrm{g} \mathrm{kg}^{-1},<\mathrm{LOQ}-296 \mu \mathrm{g} \mathrm{kg}^{-1}$,

$15<\mathrm{LOQ}-23 \mu \mathrm{g} \mathrm{kg}^{-1}$ for biscuits, crisp bread, crackers and bread sticks. Acrylamide was

16 significantly higher in samples when ammonium hydrogen carbonate had been used as a 17 rising agent and high fibre content $(>5 \%)$ used in the formulation, but lower when

18 functional ingredients such as polyols were used. An estimation of the acrylamide 19 dietary exposure related to biscuits and bread-derivatives was calculated as $0.082 \mu \mathrm{g} \mathrm{kg}^{-}$

$20{ }^{1}$ day $^{-1}$. Estimated dietary intake ranged from 0.002 to $0.058 \mu \mathrm{g} \mathrm{kg}^{-1}$ day $^{-1}$ for crackers 21 and biscuits respectively.

23 Keywords: Acrylamide, biscuits, crisp bread, crackers, bread sticks, food contaminants. 


\section{Introduction}

3 The detection of acrylamide, which has been classified as a probable carcinogen by the

4 International Agency for Research on Cancer (IRAC, 1994), in a large variety of heated

5 foods (Tareke et al. 2002) has created much concern among regulating authorities, the

6 food industry and the public. Consequently, worldwide monitoring of acrylamide in

7 different food types was started (Lineback et al. 2005). Extensive data on levels of

8 acrylamide have been collected by the European Commission (2005) and by the US

9 Food and Drug Administration (2004). Among the most important matrices included in

10 the European monitoring database are potato chips, crispbread, breakfast cereals and

11 biscuits.

12

13 Acrylamide is formed in the Maillard reaction, reducing sugars such as glucose and

14 fructose, and the amino acid asparagines being the major reactants (Stadler et al. 2002,

15 2004; Zyzak et al. 2003). Two mechanisms, varying in details, have been proposed

16 (Becalski et al. 2003; Zyzak et al. 2003). However, evidence clearly points to the

17 reaction between asparagine and reducing sugars as the main culprit.

19 It is now well-established that processing conditions such as time, temperature, and

20 matrix influence acrylamide formation and degradation (Friedman, 2003). Acrylamide

21 formation was found to occur during the browning process at temperatures above 120

$22{ }^{\circ} \mathrm{C}$ (Mottram et al. 2002; Yaylayan et al. 2003). In the case of starchy products (mainly

23 bakery) acrylamide contents up to $2000 \mu \mathrm{g} / \mathrm{kg}$ were observed (Croft et al. 2004). The

24 highest contents were often found in products, such as gingerbread, prepared with the

25 baking agent ammonium hydrogen carbonate (Amrein et al. 2004; Konings et al. 2003) 
1 which has been shown that strongly promotes the acrylamide formation in sweet bakery

2 (Biedermann et al. 2003; Graf et al. 2006).

3

4 As stated above investigations about acrylamide formation has been focused on food

5 commodities with high acrylamide formation, such as potato-derived foodstuffs, or with

6 significant impact on the dietary population habits, like cereal-based foodstuffs. Biscuits

7 and bread-derivatives comprise a huge family of products obtained by baking a variety

8 of cereal crops. Generally, manufacture of both kinds of products involves different

9 steps such as mixture of ingredients and kneading, dough fermentation (mainly in bread

10 crust and bread sticks), baking -up to $250^{\circ} \mathrm{C}$ for $15-30 \mathrm{~min}$ and in some cases a final

11 toasting step (Ramirez-Jimenez et al. 2000). This last step favour the main chemical

12 reactions involved during biscuits or bread derivatives manufacture, the Maillard

13 reaction and caramelisation, which are responsible for the colour and flavour of these

14 kinds of products (Ramirez-Jimenez et al. 2000).

16 The study presented here should give an overview of the acrylamide content of

17 commercial biscuits and bread derivatives marketed in Spain. These products, because

18 of their relatively widespread consumption, could be a key source of acrylamide in the

19 Spanish diet. Therefore, the relationship between acrylamide intake and population

20 factors is also presented. In addition the correlation among levels of acrylamide and

21 compositional parameters of the samples (i.e. presence of ammonium hydrogen

22 carbonate, dietary fibre content and biscuit speciality) was investigated.

\section{Materials and methods}

25 Samples 
1 Experiments were conducted with a series of commercial biscuits (62 samples), bread 2 crust (24 samples), bread sticks (10 samples) and crackers (11 samples) randomly 3 purchased on different supermarkets from the Autonomous Community of Madrid 4 (Spain). The distribution of samples was representative of the proportions of these food 5 commodities in the Spanish market. Samples (300-500 g) were mixed and finely ground 6 to ensure homogeneous distribution. Sub-samples $(200 \mathrm{~g})$ were divided into 4 7 containers and stored under vacuum and light protected at $4^{\circ} \mathrm{C}$ until analysis.

8

9 Chemicals and materials

$10 \quad\left[{ }^{13} \mathrm{C}_{3}\right]$-acrylamide (isotopic purity 99\%) was from Cambridge Isotope Labs (Andover, 11 MA, USA). Acrylamide (99\%), potassium ferrocianide (Carrez I), zinc acetate (Carrez 12 II) were from Sigma-Aldrich (St-Louis, MO, USA). Acetic acid (ultrapure grade) and 13 Pronase E were from Merck (Darmstadt, Germany). Methanol and acetonitrile (HPLC 14 grade) were from Scharlau (Barcelona, Spain). The solid-phase extraction (SPE) 15 cartridges Isolute ${ }^{\circledR}$ Multimode $(500 \mathrm{mg}, 3 \mathrm{ml}$ ) were from IST (Hewgoed, Mid16 Glamorgan, UK)

\section{Acrylamide standard and reagents}

19 Stock solutions of acrylamide $\left(0.01 \mathrm{mg} \mathrm{ml}^{-1}\right)$ and $\left[{ }^{13} \mathrm{C}_{3}\right]$-acrylamide $\left(5 \mu \mathrm{g} \mathrm{ml}^{-1}\right)$ were 20 prepared by dissolving the compounds in Milli-Q water and methanol respectively. 21 These solutions were then appropriately diluted with Milli-Q water (Millipore Corp., 22 Madrid, Spain) to prepare working standards at $1.0 \mu \mathrm{g} \mathrm{ml}^{-1}$. All stock solutions and 23 working standards were stored light-protected in a refrigerator at $4^{\circ} \mathrm{C}$ up to 3 months. 24 Carrez I solution was prepared by dissolving $15 \mathrm{~g}$ of potassium ferrocianide in $100 \mathrm{ml}$ 25 of water and Carrez II solution by dissolving $30 \mathrm{~g}$ of zinc acetate in $100 \mathrm{ml}$ of water. 
2 Acrylamide analysis

3 Acrylamide was analysed as described by Rufian-Henares et al. (2006) with some minor

4 modifications.

5 Sample extraction. Sample powder $(0.75 \mathrm{~g})$ was weighed with a precision of $0.1 \mathrm{mg}$ and 6 suspended with $8 \mathrm{ml}$ of MilliQ water in polypropylene centrifugal tubes. Mixture was 7 spiked with $200 \mu \mathrm{l}$ of a $5 \mu \mathrm{g} \mathrm{ml}^{-1}\left[{ }^{13} \mathrm{C}_{3}\right]$-acrylamide methanolic solution as internal 8 standard and later homogenized. Acrylamide extraction was performed at room

9 temperature for 20 minutes, and 10 seconds shaking every 10 minutes. In order to 10 clarify the solution, $0.5 \mathrm{ml}$ of each Carrez I and Carrez II solutions were added and 11 finally the mixture was centrifuged $\left(9000 \mathrm{~g} ; 10 \mathrm{~min} ; 4^{\circ} \mathrm{C}\right)$.

13 Sample clean up. Isolute ${ }^{\circledR}$ Multimode SPE cartridges were preconditioned with $2 \mathrm{ml}$ 14 methanol, $2 \mathrm{ml}$ water and $2 \mathrm{ml}$ air to remove excessive water. An aliquot of the clear 15 supernatant $(1 \mathrm{ml})$ was loaded onto the cartridge at a flow rate of $2 \mathrm{ml} \mathrm{min}^{-1}$. Then $2 \mathrm{ml}$ 16 of air were passed and finally acrylamide was eluted with $1 \mathrm{ml}$ of water at the same 17 flow rate. The solution was filtered through a $0.45 \mu \mathrm{m}$ filter into an amberlite LC-MS 18 vial.

20 LC-MS analysis. Sample extracts and calibration standards were analyzed on an Agilent 211100 liquid chromatograph coupled to an Agilent Quadrupole MS detector (Agilent 22 Technologies, Palo Alto, CA, USA). Analytical separation was achieved with a Luna 23 ODS2 (25 x $0.46 \mathrm{~cm}, 5 \mu \mathrm{m}$; Phenomenex, Torrance, CA, USA) at $32^{\circ} \mathrm{C}$. Isocratic 24 elution was achieved with a mobile phase of acetic acid-methanol-Milli-Q water $25(0.1: 2.5: 97.4)$ at a flow rate of $0.8 \mathrm{ml} \mathrm{min}^{-1}$. The injection volume was $80 \mu \mathrm{l}$. 
1 Electrospray ionization in the positive ionization mode was used. The MS detector

2 operated in selected ion monitoring (SIM) mode at $\mathrm{m} / \mathrm{z}$ ratios of 72.1 and 75.1 for 3 acrylamide and $\left[{ }^{13} \mathrm{C}_{3}\right]$-acrylamide respectively. Under these chromatographic 4 conditions, acrylamide eluted at $6.8 \mathrm{~min}$. A delay time of $3 \mathrm{~min}$ was selected to avoid 5 the introduction of coextracted matrix components into the MS instrument prior 6 acrylamide elution. The needle and cone voltages were set at $3.0 \mathrm{kV}$ and $100 \mathrm{~V}$ 7 respectively. Nitrogen was used as nebulizer gas $\left(12.01 \mathrm{~h}^{-1}\right)$ and the source temperature 8 was set at $300^{\circ} \mathrm{C}$.

9

10 Quantitation. Acrylamide was quantified using a linear calibration function that was 11 established with standard solutions of acrylamide and $\left[{ }^{13} \mathrm{C}_{3}\right]$-acrylamide dissolved in 12 Milli-Q water (25 to $1000 \mu \mathrm{g} \mathrm{l}^{-1}$ ). Acrylamide contents in sample extracts were 13 calculated from the calibration slope and intercept value, taking into account the 14 recovery calculated by means of $\left[{ }^{13} \mathrm{C}_{3}\right]$-acrylamide slope. Limit of quantification (LOQ) 15 was $30 \mu \mathrm{g} \mathrm{kg}^{-1}$ on the basis of signal-to-noise ratio of $3: 1$.

17 Statistical. Statistical significance of data was tested by one-way analysis of the 18 variance (ANOVA) (Table 5), followed by Duncan Test to compare means that showed 19 significant variation $(P<0.05)$. Analyses were performed using Statgraphics Plus, 20 version 5.1, 2001. At least, two independent analyses were carried out per sample.

\section{Results and discussion}

24 Sample analysis 
1 The analysis of acrylamide was carried out by means of an analytical methodology

2 previously established for potato chips (Rufian-Henares and Morales 2006) and

3 subsequently adjusted for breakfast cereals (Rufian-Henares et al. 2006). The procedure

4 was accurate, precise and had adequate sensitivity to detect the acrylamide content of 5 the targeted food commodities

6

7 Bread derivatives. A total of 45 bread types were studied: 24 crispbreads, 10 bread

8 sticks and 11 crackers. A detailed study of acrylamide distribution was carried out, and

9 a box-and-whisker plot was used since this graphical presentation uses a non-parametric

10 test (Figure 1A). Acrylamide ranged from < LOQ - $151 \mu \mathrm{g} \mathrm{kg}^{-1}$ for crispbread, with a 11 mean value of $87 \mu \mathrm{g} \mathrm{kg}^{-1}$ and a median of $100 \mu \mathrm{g} \mathrm{kg}$. In the case of crackers 12 acrylamide ranged from < LOQ - $296 \mu \mathrm{g} \mathrm{kg}^{-1}$, being the mean value $140 \mu \mathrm{g} \mathrm{kg}^{-1}$ and the 13 median $155 \mu \mathrm{g} \mathrm{kg}^{-1}$. Finally, in the case of bread sticks acrylamide ranged from <LOQ $14323 \mu \mathrm{g} \mathrm{kg}^{-1}$ with a mean value of $157 \mu \mathrm{g} \mathrm{kg}^{-1}$ and a median of $139 \mu \mathrm{g} \mathrm{kg}^{-1}$.

16 Similar values where reported by other authors (i.e. Murkovic. 2004; Senyuva and

17 Gökmen. 2006; Yusa et al. 2006) who found acrylamide levels from $11-210 \mu \mathrm{g} \mathrm{kg}^{-1}$ for 18 crisp bread and, in the case of crackers values ranging from $<30-582 \mu \mathrm{g} \mathrm{kg}^{-1}$ (i.e.

19 Riediker and Stadler, 2003; Senyuva and Gökmen. 2005). The statistical treatment

20 showed that the acrylamide levels of crisp bread are significantly lower $(\mathrm{p}<0.05)$ than

21 that of bread sticks and crackers. The composition of both crispbread and bread sticks is

22 similar (mainly wheat flour, baking powder, salt and water) whereas in the case of crackers sodium hidrogencarbonate is used instead of baking powder. Taking into account these similarities, the differences in the acrylamide content could come from the different baking conditions (time and temperature) applied to the products. 
2 Many studies have been accomplished to find strategies to minimize the levels of

3 acrylamide. This objective can be achieved either by modifying the processing

4 parameters such as $\mathrm{pH}$, temperature/time of heating or acting on precursors or key

5 intermediates. WHO and the Scientific Committee for Food of the European Union

6 called for strategies to reduce acrylamide formation to a minimum by implementing the

7 ALARA principle (as low as reasonably achievable). In this sense the German Federal

8 Office of Consumer Protection and Food Safety (BVL, 2004) stated a signal value of

$9560 \mu \mathrm{g} \mathrm{kg}^{-1}$ for bread derivatives, as a concept of minimisation. Signal value is defined

10 as lowest level of the $10 \%$ containing the highest level of acrylamide. Then, if

11 acrylamide contents are above this signal value, the food producers are aware to take

12 adequate actions to lower the contents. As stated if Figure 2A, acrylamide values ranged

13 from < LOQ - $323 \mu \mathrm{g} \mathrm{kg}^{-1}$ for bread derivatives Then, if the same concept is applied in

14 our survey none of the samples levels was higher than $560 \mu \mathrm{g} \mathrm{kg}^{-1}$. In this sense,

15 because of the lower values of the bread derivatives marketed in Spain, a signal value of

$16222 \mu \mathrm{g} \mathrm{kg}^{-1}$ was established for the whole group. However, if the samples are divided

17 into the three original groups, the obtained signal values for crisp bread, bread sticks

18 and crackers are 129,293 and $232 \mu \mathrm{g} \mathrm{kg}^{-1}$ respectively. This is an important issue taking

19 into account that the California Environmental Protection Agency (Office of

20 Environmental Health Hazard Assessment) has proposed recently an alternative cancer

21 risk level, calculated to result in one excess case of cancer in an exposed population of

2210000 and assuming lifetime exposure, when consuming bread and cereals with an

23 acrylamide concentration lower than $200 \mu \mathrm{g} \mathrm{kg}^{-1}$ (OEHHA. 2005). 
1 Biscuits. 62 samples from 15 different producers where studied. In the case of biscuits

2 the acrylamide content ranged from < LOQ - $2085 \mu \mathrm{g} \mathrm{kg}^{-1}$, with an average value of

$3423 \mu \mathrm{g} \mathrm{kg}^{-1}$ and a median of $268 \mu \mathrm{g} \mathrm{kg}^{-1}$. In addition, as shown in the box-and-whisker

4 plot (Figure 1B), eight outliners where found, all of them with acrylamide contents

5 higher than $1000 \mu \mathrm{g} \mathrm{kg}^{-1}$. Similar values have been reported by other authors (i.e.

6 Murkovic. 2004; Senyuva and Gokmen. 2006; Yusa et al. 2006) who found acrylamide

7 levels up to $1060 \mu \mathrm{g} \mathrm{kg}^{-1}$. When the statistical treatment was applied to the biscuits and

8 bread derivatives groups, it was found that biscuits presents a statistically significant

9 ( $\mathrm{p}<0.05)$ higher acrylamide content. Contrary to the group of bread derivatives, the

10 composition of biscuits is quite different and complex because different ingredients

11 such as reducing sugars are usually added (glucose and fructose mainly added as corn

12 syrups), fats (including $\omega_{3}$-PUFAs), technological agents (ammonium and sodium

13 hydrogencarbonate), etc. It is well established that one of the components that promote

14 the generation of acrylamide are reducing sugars (Friedman. 2003; Stadler et al. 2004;

15 Zyzak et al. 2003). In addition it has been shown that the baking agent ammonium

16 hydrogen carbonate strongly promotes the acrylamide formation (Amrein et al. 2004;

17 Biedermann et al. 2003; Graf et al. 2006; Konings et al. 2003). Then, because of the

18 presence of a higher content of acrylamide precursors in biscuits, their higher

19 acrylamide content is a logical consequence.

21 As described previously, biscuits comprise a heterogeneous food commodities group because of they are composed by a great variety of ingredients. Then, in order to find

23 out the possible differences in the acrylamide content, biscuits were grouped according to the biscuit speciality, presence of ammonium hydrogen carbonate and dietary fibre 
1 the first analysis showed no statistical differences (data not shown) but it was found a

2 wide distribution among groups of the outliners of Figure 2B. Then, because of their

3 high acrylamide content the mean values of the different groups was slanted. According

4 to the table of composition -supplied by the manufacturers- it was found that the

5 outliners were just addressed to samples with ammonium hydrogencarbonate as the sole

6 raising agent, in contrast with the other 54 samples where different proportions of

7 sodium and ammonium hydrogencarbonate was used. In this sense it could be thought

8 that a higher amount of ammonium hydrogencarbonate was used for the manufacture of

9 the outliners and, because this raising agent enhance the acrylamide generation (Amrein

10 et al. 2004; Biedermann et al. 2003; Graf et al. 2006; Konings et al. 2003) a larger

11 amount of acrylamide was formed. This hypothesis explains the statistically significant

12 differences $(\mathrm{p}<0.05)$ obtained between the group where ammonium hydrogen carbonate

13 is the unique raising agent and those with other agents added (mean acrylamide content

14 of 1549 and $230.4 \mu \mathrm{g} \mathrm{kg}^{-1}$ respectively).

16 Taking into account the explanation given above, the outliers were removed for the rest

17 of the statistical treatment. Biscuits were classified into three groups based on the health

18 orientation, which is closely related to their composition: those mainly used for

19 breakfast $(\mathrm{n}=21)$, those enriched with functional ingredients $(\mathrm{n}=15)$ such as

20 conjugated linoleic acid, $\omega_{3}$-PUFA, polyols, soy extracts, or L-carnitine, and finally

21 those fibre enriched $(\mathrm{n}=18)$. Enriched biscuits showed significantly $(\mathrm{p}<0.05)$ lower

22 values of acrylamide (83 vs. 247 and $284 \mu \mathrm{g} \mathrm{kg}^{-1}$ for breakfast and fibre enriched

23 biscuits respectively). It was found that most of the enriched biscuits had polyols (such

24 as maltitol or lactitol) and potato starch replacing the addition of glucose and/or

25 fructose. This replacement give rise to a decrease on the reducing sugar content, then 
1 not favouring the generation of acrylamide. Moreover the enriched biscuits are

2 elaborated by adding other kind of flours such as rice or malt. Because of, in the case of

3 breakfast cereals it has been shown that a higher potential in acrylamide formation in

4 wheat-based cereals followed by corn, oat and rice (CIAA. 2005; Rufian-Henares et al.

5 2006) it is plausible that the decrease on the wheat flour content reduce the acrylamide

6 generation in biscuits.

7

8 Biscuits usually have dietary fibre contents of about $3-4 \%$, but when enriched with

9 wheat-bran and/or whole wheat flour, dietary fibre increases up to $10-30 \%$. As

10 illustrated in Table 1, there were statistically significant differences in the acrylamide

11 content between the dietary fibre added biscuits $\left(283 \pm 38.1 \mu \mathrm{g} \mathrm{kg}^{-1} ; \mathrm{n}=18\right.$;

12 fibre content $>5 \%)$ and not dietary fibre-added $\left(166 \pm 31.0 \mu \mathrm{g} \mathrm{kg} \mathrm{g}^{-1} ; \mathrm{n}=44\right.$; fibre

13 content $<5 \%$ ), results which are in accordance to those previously reported for

14 breakfast cereals (Rufian-Henares et al. 2006). Similar behaviour was reported by

15 Senyuva and Gökmen (2006) who found that the acrylamide content of biscuits with

16 dietary fibre was higher than that of the usual biscuits (486 and $261 \mu \mathrm{g} \mathrm{kg} \mathrm{g}^{-1}$

17 respectively). This could be explained by the fact that asparagine, the main precursor of acrylamide in cereal products (RHM Technologies 2005) is concentrated in the bran,

19 particularly in wheat-bran (CIAA. 2005).

21 Finally, the relationship was studied between the acrylamide content of biscuits and the

22 signal value stated by the German Federal Office of Consumer Protection and Food

23 Safety (BVL, 2004). This organization stated a signal value of $575 \mu \mathrm{g} \mathrm{kg}^{-1}$ for adult

24 population and $360 \mu \mathrm{g} \mathrm{kg}^{-1}$ for children. As depicted in Figure 2B, when applying the

25 same concept most of the samples (80\%) are under the $575 \mu \mathrm{g} \mathrm{kg}^{-1}$ level. Taking into 
1 account the results in this reported survey, a signal level of $1283 \mu \mathrm{g} \mathrm{kg}^{-1}$ is found

2 although, if the eight outliners are omitted (because of the explanation given above

3 concerning to the addition of ammonium hydrogen carbonate), a corrected level of 519

$4 \quad \mu \mathrm{g} \mathrm{kg}^{-1}$ is obtained, quite similar to that of the German Office one.

5

\section{Acrylamide intake mediated by biscuits and bread derivatives}

7 Estimating consumer dietetic exposure to acrylamide is a high priority for governments

8 and industry alike. Extensive research is underway to determine the extent to which

9 acrylamide found in food is bioavailable and to identify methods to reduce levels in

10 order to decrease consumer exposures. Consumer exposure assessments will need to be

11 conducted in order to gauge the utility of various control options. It is particularly

12 important to be able to assess the impact of proposed changes to the food supply

13 including the impact of modifications in processing and cooking procedures on

14 consumer exposures.

16 In order to estimate the dietary exposure of Spanish consumers to acrylamide from

17 biscuits and bread derivatives, the intake of these food supplies was used (MAPA

18 2005). The results, collected in Table II, have been expressed as $\mu \mathrm{g} \mathrm{kg}^{-1} \mathrm{day}^{-1}$ taking

19 into account a mean body weight of $70 \mathrm{~kg}$. For total population the intake of acrylamide

20 ranged from $0.002-0.058 \mu \mathrm{g} \mathrm{kg}^{-1} \mathrm{day}^{-1}$ for crackers and biscuits respectively. In the

21 case of biscuits, their contribution to the total daily intake of acrylamide is intermediate

22 to that of breakfast cereals $\left(0.038 \mu \mathrm{g} \mathrm{kg}^{-1} \mathrm{day}^{-1}\right)$ and potato chips $\left(0.093 \mu \mathrm{g} \mathrm{kg}^{-1}\right.$ day

$23^{1}$ ) previously reported (Rufian-Henares et al. 2006; Rufian-Henares and Morales 2006). 
1 There are considerable differences even between many of the European countries, due

2 to the differences in food consumption patterns and cooking traditions. Irrespective of

3 the cultural differences in nutritional habits, the overall daily intake is about $0.4 \mu \mathrm{g} \mathrm{kg}^{-1}$

4 day $^{-1}$ according to the most recent FDA estimates, basically confirming earlier

5 estimations from the US and several European authorities (Dybing et al. 2005).

6 Assuming a mean Spanish intake of acrylamide similar to that of other European

7 countries, a mean daily intake of acrylamide of $0.2 \mu \mathrm{g} \mathrm{kg}^{-1}$ day ${ }^{-1}$ can be calculated

8 assuming only the intake of the above reported foods (bread-derivatives, biscuits,

9 breakfast cereals, potato chips). Estimations of WHO of the average intake of

10 acrylamide for the general population ranged between $0.3-0.8 \mu \mathrm{g} \mathrm{kg}^{-1}$ day ${ }^{-1}$. It was

11 supposed that children and adolescents would generally have exposures up to two to

12 three times those of adult consumers when expressed on a body weight basis (WHO,

13 2002).

The foods that contribute most to acrylamide exposure vary depending upon the

16 population's eating habits and the way the foods are processed and prepared. Generally,

17 the most important categories of food appear to be: fried potato products such as French

18 fries and chips, ready-to-eat breakfast cereals, baked goods such as cookies, pies and

19 cakes, brewed coffee and breads, according to the most recent results of the FDA/ CFSAN (Dybing et al. 2005). In this survey representative from the Spanish market 21 contribution of biscuits, crisp bread, crackers and bread sticks will be of 14.5, 4.75, 0.5 and $0.75 \%$ respectively of the estimated dietary intake of acrylamide. In addition the contribution of potato chips and breakfast cereals will be of a $23 \%$ and a $9.5 \%$ respectively (Rufian-Henares and Morales, 2006; Rufian-Henares et al. 2006). 
1 In consumer exposure assessments it is also important to know whether there are

2 significant differences in exposures in different sub-groups of the population. In this

3 sense the exposure to acrylamide related to the those foodstuffs studied was analysed in

4 more detail taking into account socio-economic aspects (MAPA 2005). It was observed

5 that there are great differences in the intake of bread derivatives depending on the socio-

6 economic community studied, almost doubling their intake. When the number of family

7 members was analysed it could be stated that the higher intakes was in families

8 composed of 1 or 2 independent adults whereas the lower intakes where found in young

9 couples with children. In the higher cases the biscuits contribution turned from 14.5 to

$1020 \%$ of the overall acrylamide intake. In the case of the socio-economic status the

11 exposure to acrylamide is higher in upper class due to their higher biscuit intake.

12 Contrary lower class showed higher bread derivatives intake whereas biscuits

13 consumption decreased. Finally, taking into account the population size it was found

14 that the lower acrylamide intake was recorded in cities with more than 500,000

15 inhabitants whereas the maximum intake was in localities with low-intermediate

16 number of inhabitants.

18 Conclusions

19 This work describes the determination of acrylamide in biscuits and bread derivatives

20 cereals marketed in Spain, as a previous survey of foodstuffs had indicated these to

21 contain acrylamide. The data was used to determine the dietary intake of acrylamide for

22 the Spanish population for risk assessment purposes, it is estimated a mean daily dietary

23 intake of acrylamide of $0.082 \mu \mathrm{g} \mathrm{kg}^{-1}$ day $^{-1}$ for which the contribution of biscuits was

24 higher than that of bread derivatives. It was also shown that in the case of biscuits,

25 higher acrylamide content was found in those manufactured with ammonium hydrogen 
1 carbonate as the only raising agent and in those biscuits with higher proportions of

2 dietary fibre. Conversely, lower acrylamide content was found in biscuits enriched with

3 functional ingredients such as polyols.

4

\section{References}

6 Amrein TM, Schönbächler B, Escher F, Amado R. 2004. Acrylamide in gingerbread:

7 Critical factors for formation and possible ways for reduction. Journal of Agricultural 8 and Food Chemistry 52:4282-4288.

9 Becalski A, Lau BP, Lewis D, Seaman SW. 2003. Acrylamide in foods: occurrence, 10 sources, and modelling. Journal of Agricultural and Food Chemistry 51:802-808.

11 Biedermann M, Grob K. 2003. Model studies on acrylamide formation in potato, wheat 12 flour and corn starch; ways to reduce acrylamide contents in bakery ware. 13 Mitteilungen aus Lebensmitteluntersuchung und Hygiene 94:406-422.

14 CIAA, Confederation of the Food and Drink Industries of the UE (2005) The CIAA 15 Acrylamide “Toolbox”, rev. 6, September, CIAA, Brussels

16 Croft M, Tong P, Fuentes D, Hambridge T. 2004. Australian survey of acrylamide in 17 carbohydrate-based foods. Food Additives and Contaminants 21:721-736.

18 Dybing E, Farmer PB, Andersen M, Fennell TR, Lalljie SPD, Müller DJG, Olin S, 19 Petersen BJ, Schlatter J, Scholz G, Scimeca JA, Slimani N, Törnqvist M, Tuijtelaars S, Verger P. 2005. Human exposure and internal dose assessments of acrylamide in food. Food and Chemical Toxicology 43:365-410.

22 European Commission. 2005. Directorate General Joint Research Centre, Institute for 23 Reference Materials and Measurements. (available at: http://www.irmm.jrc.be/html activities/Acrylamide/database.html) (accessed on 12 February 2005). 
1 Food and Drug Administration

(FDA) (available

at:

2 http://www.cfsan.fda.gov/_dms/acrydata.html\%20via) (accessed April 2004).

3 Friedman M. 2003. Chemistry, biochemistry, and safety of acrylamide. A review.

4 Journal of Agricultural and Food Chemistry 51:4504-4526.

5 German Federal Office of Consumer Protection and Food Safety (BVL, 2004)

6 (http://www.bvl.bund.de/cln_027/nn_521172/EN/01_Food/04_Acrylamid_en/05

$7 \quad$ Signalwerte_en/signalwerte_node.html_nnn=true) (accessed on June 2005).

8 Graf M, Amrein, TM, Graf S, Szalay R, Escher F, Amado R. 2006. Reducing the

9 acrylamide content of a semi-finished biscuit on industrial scale. LWT - Food

$10 \quad$ Science and Technology 39:7243728.

11 IARC. (1994, 08/26/1997). Volume 60: Some industrial chemicals, Monographs on the 12 evaluation of carcinogenic risk to humans. Some industrial chemicals, Lyon, IARC, 13 Vol. 60.

14 Konings EJM, Baars AJ, van Klaveren JD, Spanjer MC, Rensen PM, Hiemstra M, van 15 Kooij JA, Peters PWJ. 2003. Acrylamide exposure from foods of the Dutch 16 population and an assessment of the consequent risk. Food and Chemical Toxicology $17 \quad 41: 1569-1579$.

18 Lineback D, Wenzl T, Ostermann OP, De La Calle B, Anklam E. 2005. Overview of 19 acrylamide monitoring database. Journal of AOAC International 88:246-252.

20 MAPA 2005. La alimentación en España Ministerio de Agricultura, Pesca y 21 Alimentación Ed. Madrid, Spain.

22 Mottram DS, Wedzicha BL, Dodson AT. 2002. Acrylamide is formed in the Maillard 23 reaction. Nature 419:448-449.

24 Murkovic M. 2004. Acrylamide in Austrian foods Journal of Biochemical and 25 Biophysical Methods 61:161-167. 
1 OEHHA (California Environmental Protection Agency) Office of Environmental

2 Health Hazard Assessment. (available at www.oehha.org/prop65/law/pdf.zip/Notice-

3 \%2012705eAltRiskrevised.pdf) (accessed on June 2005).

4 Ramírez-Jiménez A, García-Villanova B, Guerra-Hernández E. 2000.

5 Hydroxymethylfurfural and methylfurfural content of selected bakery products Food

$6 \quad$ Research International 2000 33:833-838.

7 RHM Technologies. Presentation at the FSA Process Contaminants meeting April. $8 \quad 2005$, London, UK.

9 Riediker S, Stadler RH. 2003. Analysis of acrylamide in food by isotope-dilution liquid

10 chromatography coupled with electrospray ionization tandem mass spectrometry.

11 Journal of Chromatography A 1020:121-130.

12 Rufian-Henares JA, Delgado-Andrade C, Morales FJ. 2006. Relationship between 13 acrylamide and thermal-processing indexes in commercial breakfast cereals: A 14 survey of Spanish breakfast cereals. Molecular Nutrition and Food Research 50:75615762.

16 Rufian-Henares JA, Morales FJ. 2006. Determination of acrylamide in potato chips by 17 a reversed-phase LC-MS method based on a stable isotope dilution assay. Food 18 Chemistry 97:555-562.

19 Senyuva HZ, Gokmen V. 2005. Survey of acrylamide in Turkish foods by an in-house 20 validated LC-MS method. Food Additives and Contaminants 22:204-209.

21 Senyuva H.Z., Gökmen V. 2006. Interference-free determination of acrylamide in 22 potato and cereal-based foods by a laboratory validated liquid chromatography-mass spectrometry method. Food Chemistry 97:539-545.

24 Stadler RH, Blank I, Varga N, Robert F. Hau J. Guy PA. Robert MC. Riediker S. 2002. 25 Acrylamide from Maillard reaction products. Nature 419:449-450. 
1 Stadler RH, Robert F, Riediker S, Varga N, Davidek T, Devaud S, Goldmann T, Hau J,

2 Blank I. 2004. In-depth mechanistic study on the formation of acrylamide and other

3 vinylogous compounds by the Maillard reaction. Journal of Agricultural and Food

$4 \quad$ Chemistry 52:5550-5558.

5 Tareke E, Rydberg P, Karlsson P, Eriksson S, Törnqvist M. 2002. Analysis of 6 acrylamide, a carcinogen formed in heated foodstuffs. Journal of Agricultural and $7 \quad$ Food Chemistry 50:4998-5006.

8 WHO (World Health Organisation, 2002) FAO/WHO Consultation of the Health

9 Implications of Acrylamide in Food. Summary Report of a meeting held in Geneva,

10 25-27 June 2002. (available at http://www.who.int/fsf/Acrylamide) (accessed on 11 June 2005).

12 Yaylayan VA, Wnrowski A, Perez LC. 2003. Why asparagine needs carbohydrates to 13 generate acrylamide. Journal of Agricultural and Food Chemistry 51:1735-1757.

14 Yusa V, Quinta G, Pardo O, Marti P, Pastor A. Determination of acrylamide in foods by 15 pressurized fluid extraction and liquid chromatography-tandem mass spectrometry 16 used for a survey of Spanish cereal-based foods. Food Additives and Contaminants $17 \quad 23: 237-244$.

18 Zyzak DV, Sanders RA, Stojanovic M, Tallmadge DH, Eberhart BL, Ewald DK,

19 Gruber DC, Morsch TR, Strothers MA, Rizzi GP, Villagran MD. 2003. Acrylamide 20 formation mechanism in heated foods. Journal of Agricultural and Food Chemistry $21 \quad 51: 4782-4787$. 
3 Table I. Statistical treatment for acrylamide levels in commercial biscuits grouped

4 according to the biscuit speciality, presence of ammonium hydrogencarbonate as solely

5 raising agent and dietary fibre content.

\begin{tabular}{|c|c|c|}
\hline Factor & Acrylamide $\left(\mu \mathrm{g} \mathrm{kg}^{-1}\right)$ & No. of samples \\
\hline \multicolumn{3}{|l|}{ Total } \\
\hline Mean & $423 \pm 65.6$ & 62 \\
\hline Median & 268 & \\
\hline Minimum & 15 & \\
\hline Maximum & 2085 & \\
\hline \multicolumn{3}{|c|}{ Biscuit speciality } \\
\hline Breakfast & $247 \pm 41.8^{\mathrm{a}}$ & 21 \\
\hline Enriched & $83 \pm 37.4^{b}$ & 15 \\
\hline Fibre added & $284 \pm 39.9^{\mathrm{a}}$ & 18 \\
\hline \multicolumn{3}{|c|}{ Ammonium hydrogencarbonate } \\
\hline Yes & $1549 \pm 117^{\mathrm{a}}$ & 8 \\
\hline No & $230 \pm 36.2^{b}$ & 54 \\
\hline \multicolumn{3}{|c|}{ Dietary fibre content } \\
\hline$<5 \%$ & $283 \pm 38.1^{\mathrm{a}}$ & 18 \\
\hline$>5 \%$ & $166 \pm 31.0^{b}$ & 36 \\
\hline
\end{tabular}


1 Table II. Contribution of commercial bread derivatives and biscuits to the acrylamide intake ${ }^{\mathrm{a}}$ of the Spanish population.

2

\begin{tabular}{llllccc}
\hline & & & & & Food \\
Factor & Interval & Example & Crisp & Bread \\
bread & Crackers & sticks & Biscuits \\
\hline Total population & & & 0.0190 & 0.0020 & 0.0030 & 0.0580 \\
Autonomic & Maximum & Extremadura for bread derivatives and Balear Islands for biscuits & 0.0200 & 0.0030 & 0.0040 & 0.0670 \\
community & Minimum & Canary Islands for bread derivatives and Andalusia for biscuits & 0.0110 & 0.0017 & 0.0020 & 0.0410 \\
Family & Maximum & Independent adults for biscuits and couples without children for bread & 0.0230 & 0.0034 & 0.0042 & 0.0801 \\
components & Minimum & Young couples with children & 0.0100 & 0.0018 & 0.0018 & 0.0418 \\
Socio-economic & Maximum & Upper class for biscuits and middle/lower class for bread derivatives & 0.0235 & 0.0027 & 0.0042 & 0.0621 \\
status & Minimum & Upper class for bread derivatives and lower class for biscuits & 0.0116 & 0.0016 & 0.0024 & 0.0481 \\
Population & Maximum & $>2000$ Inhabitants for bread derivatives and 10 000-100 000 for biscuits & 0.0217 & 0.0027 & 0.0039 & 0.0630 \\
size & Minimum & $<500$ 000 Inhabitants & 0.0131 & 0.0020 & 0.0024 & 0.0480 \\
\hline
\end{tabular}

${ }^{\mathrm{a}}$ Results expressed as $\mu \mathrm{g} \mathrm{kg}^{-1} \mathrm{day}^{-1}$ taking into account a mean body weight of $70 \mathrm{~kg}$. 


\section{Figure Captions}

2

3 Figure 1. Box-and-whisker plot of acrylamide content in commercial bread derivatives

4 (A) and biscuits (B).

5

6 Figure 2. Bar graph of acrylamide content in commercial bread derivatives (A) and 7 biscuits (B).

8

9

10

11

12

13

14

15

16

17

18

19

20

21

22

23 
Figure 1

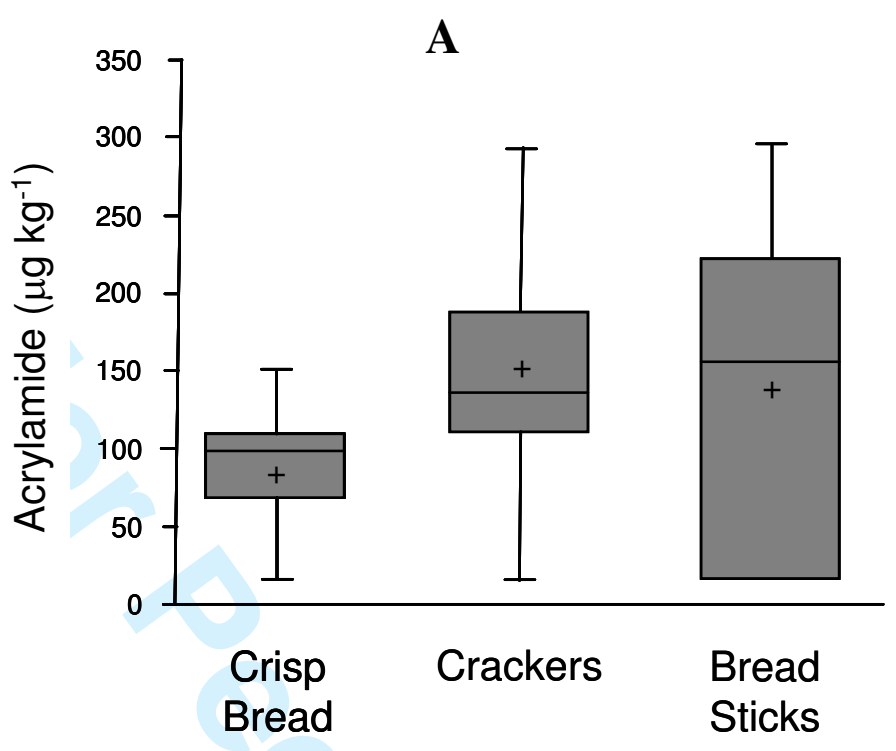

B

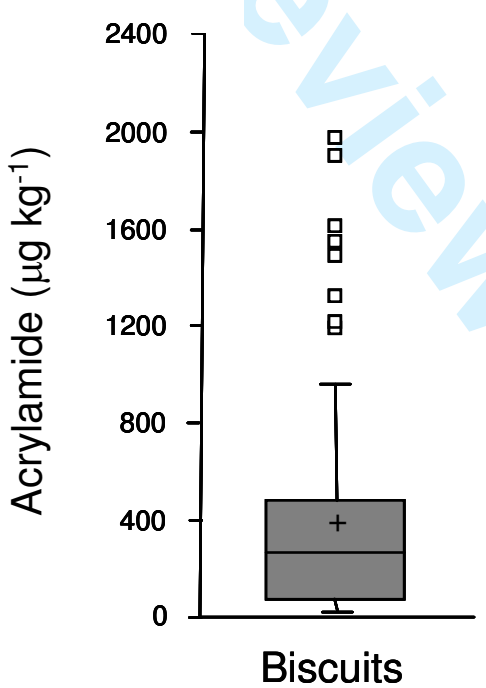

4 


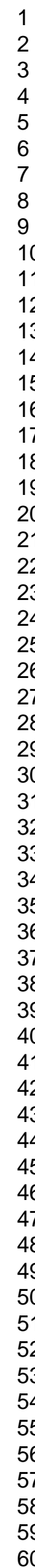

FIGURE 2A

1
2
3
4
5

A

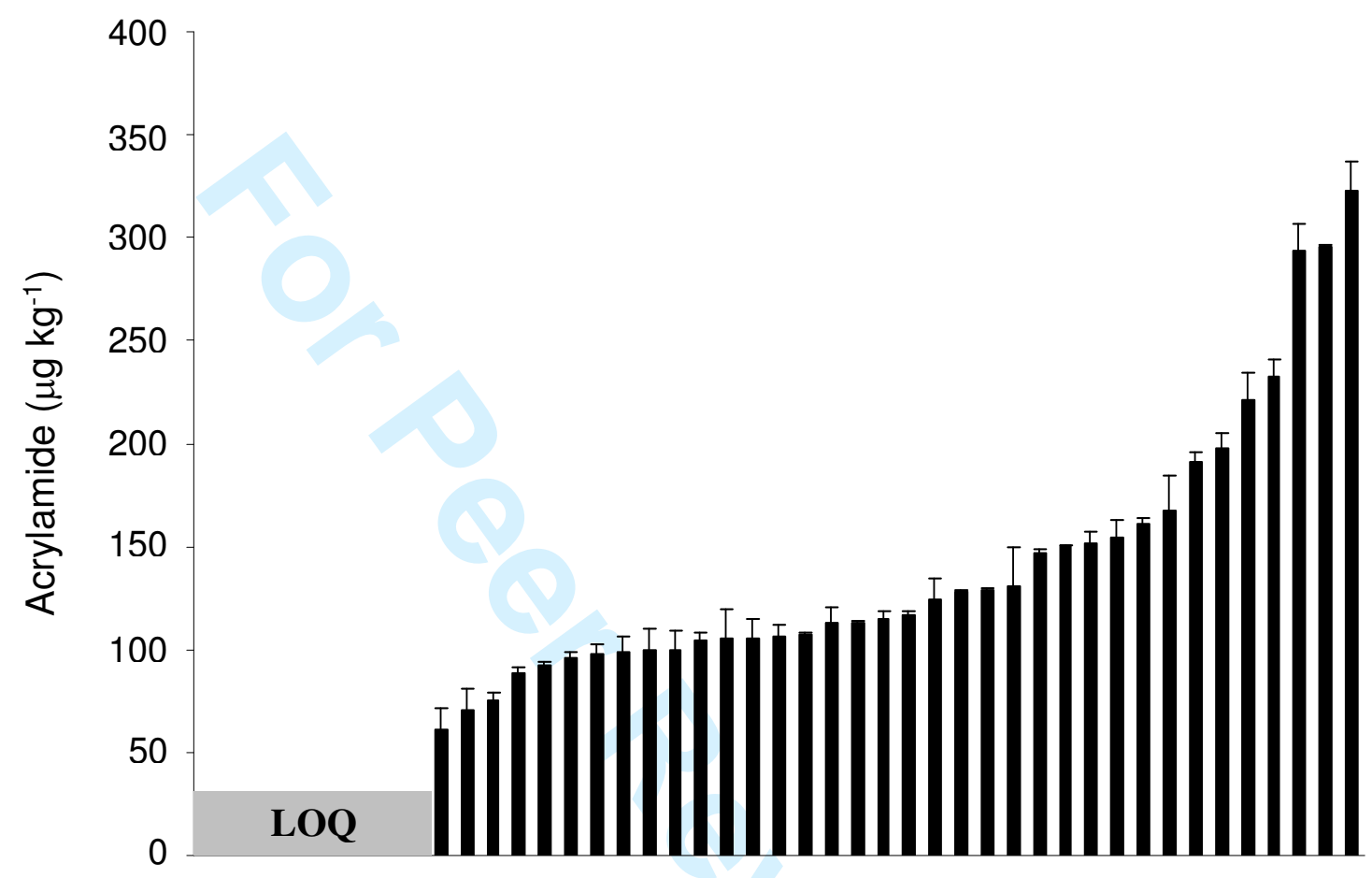

6

7

8

9 
FIGURE 2B

\section{B}

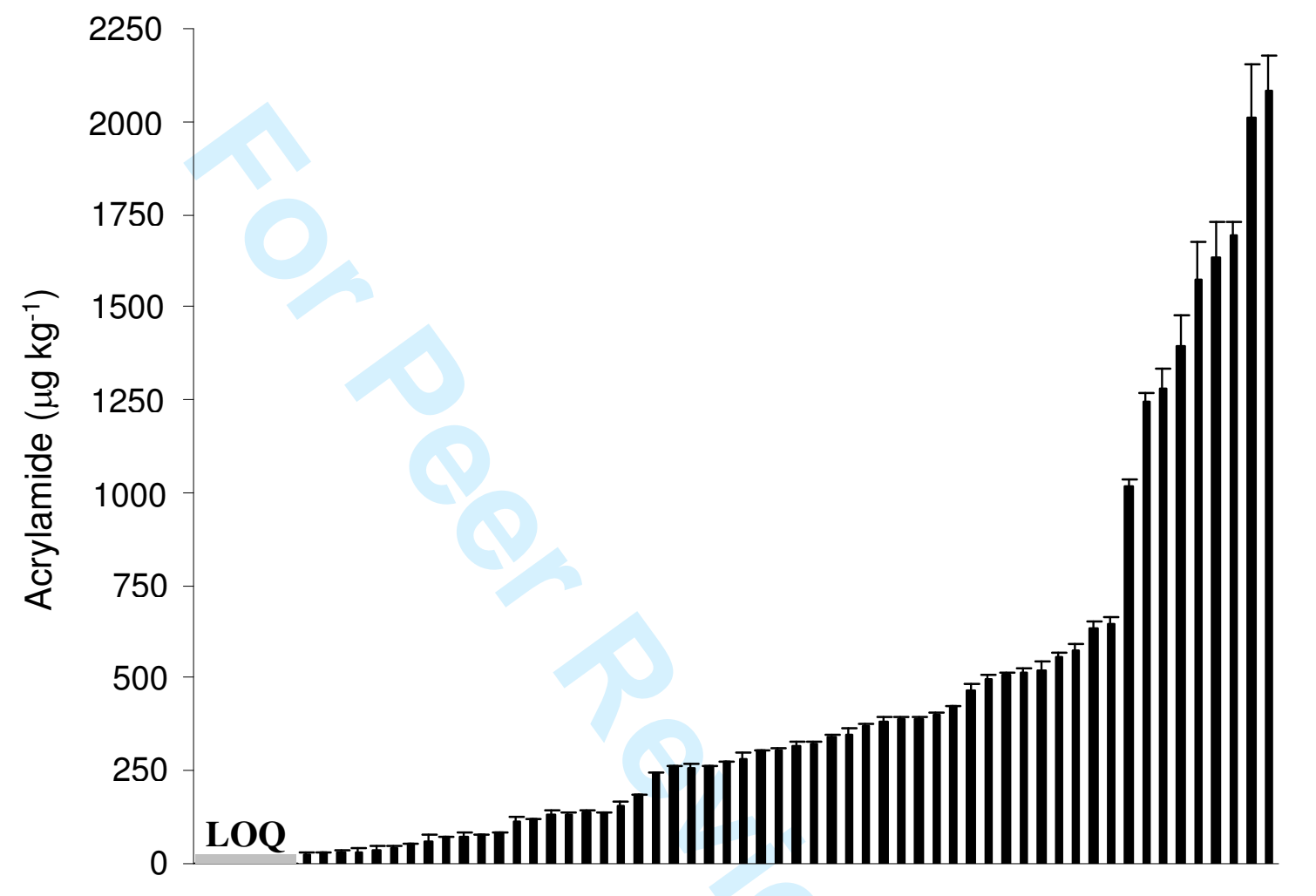

